\title{
Museum Crowdsourcing as Playful Labour
}

Crowdsourcing en el museo como entretenimiento productivo

\section{Cristiano Agostino}

\section{(2) OpenEdition}

\section{Journals}

Electronic version

URL: http://journals.openedition.org/iss/545

DOI: $10.4000 /$ iss. 545

ISSN: 2306-4161

\section{Publisher}

ICOM - International Council of Museums

\section{Printed version}

Date of publication: 1 June 2015

Number of pages: 23-37

ISSN: 2309-1290

\section{Electronic reference}

Cristiano Agostino, «Museum Crowdsourcing as Playful Labour », ICOFOM Study Series [Online] 43a | 2015, Online since 06 February 2018, connection on 30 April 2019. URL : http:// journals.openedition.org/iss/545; DOI : 10.4000/iss.545 


\title{
Museum Crowdsourcing as Playful Labour
}

\author{
Cristiano Agostino
}

\author{
History of Art - University of Edinburgh, UK
}

Thanks to the Web and its social affordances, the visitor has become a strategic agent in the contemporary museum economy in ways that seemed unlikely only a few years ago: nowadays the visitor has, more often than not, a growing negotiating power in the direction, the development and the aftermath of an exhibit, ranging from the 'soft power' of presence, through a role as informal consultant in the case of cultural sensitive material, to a fundamental PR and advertising role through social media.

Sometimes, the role of the visitor in the museum economy extends even deeper than the ad hoc context of an exhibit. More and more, museums rely on the collective intelligence (O'Reilly, 2005) of their audiences for gathering and classifying data and metadata around their massive, often poorly catalogued or tagged collections. The general assumption in this process of 'crowdsourcing' is that it entails benefits for both parties: the museum obtains generally useful information about its collections and the user's interest in them, supporting both curatorial and public goals; crowdsourcees, on the other hand, gain a sense of added value to their museum experience, and produce information that, in the end, will benefit them in the form of better tailored, significant information (Terras \& Causer, 2014; Romeo \& Blaser, 2011; Ridge, 2011). The issue of remuneration or payment is usually not considered, as 'in the public and non-profit sectors [...] volunteering has a long and consolidated tradition, and unpaid work is done for a common good' (Carletti et al., 2013, p. 225).

Outside the museum, however, harnessing of the online user's hours through free labour has recently come under heavier scrutiny (Hodson, 2013; Deng \& Joshi, 2013). A complex critique, taking the cue from Autonomist labour theories, has underlined the many ethically dubious if not outright exploitative features of the massive 'free labour' online economy of which crowdsourcing is one of the most visible, and most generally celebrated facets (Terranova, 2000). Furthermore, the remunerative use of the Web citizen's free time for free labour, under all guises, has been put in the much wider context of contemporary capitalism colonisation of non-work time through the instrument of affective labour: activity that is not remunerated, yet entices by appealing to psychological, social or cultural needs (Lazzarato, 1996; Hardt, 1999).

This essay seeks to argue for a labour-oriented assessment of such online crowdsourcing practises in the context of the public museum. In particular, I will leverage on the game-like elements of many museum crowdsourcing tools as a means to weave into the discussion issues of 'playbour' and subtle colonisation of free time by work, highlighting the function of museum crowdsourcing platforms as tools for immaterial and affective labour of the online and digital kind.

Multiple considerations contribute to making such an analysis timely 
and necessary. There is a wealth of literature, both academic and professional, discussing museum crowdsourcing in light of its achievements, its potential for enrichment and inclusive power; on the other hand, little to no effort so far has been made to contextualise such practises according to theories of labour, work and production. This self-reflective exercise seems particularly urgent due to a series of parallel, emergent trends. First of all, once the early 2000s' enthusiasm for Web 2.0 and the Social Web leaves room to more nuanced and balanced assessments, virtually all aspects of the digital economy are being scrutinised for their potentially inequality-engendering, exploitative potential; given that the contemporary museum, both within and without crowdsourcing, finds itself more and more invested in the Web realm, it is not acceptable that its online practises evade such scrutiny.

Additionally, the museum has a long history of institutional selfreflexivity, albeit often undertaken by individuals only partially within the cogs of the museum institution: one can think, for example, of Institutional Critique, Carol Duncan's attacks on the museum as an instrument of hegemony, or the professional debate that eventually led, in the past decades, toward a museum possibly better geared for constructivist education, inclusion and social justice (1995). It seems then appropriate to hold to the same level of ethical scrutiny online museum practises.

Finally, it should be understood that the relationship between the instruments the digital/online museum has at its disposal, and the political, social and ethical implications of such instruments are mutually enhancing: as I will suggest throughout the essay by resorting to tangible examples, the most successful and empowering crowdsourcing enterprises seem to be those that take into account the ethics of playbour and affective labour, harnessing them without derailing into actual exploitation.

\section{Immaterial and affective labour: politics of online capital}

While finding a precedent in Hardt and Negri's controversial indictment of global capitalism, Empire (1998), the concepts of immaterial and affective labour are more thoroughly explored by Hardt alone in his short 1999 essay 'Affective Labor'. The context that one has to keep in mind is, according to Hardt, the shift (since the early 70s) within modes of production, from industry toward services. Parallel to this is a progressive shift toward the informatisation of that same burgeoning service sector, eventually leading toward an informatisation of agriculture and industry as well (Hardt, 1999).

As Hardt acknowledges, 'the passage toward an informational economy involves necessarily a change in the quality of labour and the nature of labouring processes' (Hardt, 1999, p. 93). One, and perhaps the most important of such key changes is the increasingly immateriality of both the activities, and the goods that are exchanged in a service-based economy: information and networking themselves become the goods that are produced by a type of labour that becomes, more and more, immaterial labour - "labour that produces an immaterial good, such as a service, knowledge or communication" (Hardt, 1999, p. 94).

Even further, according to Hardt, current trends in service industries and immaterial labour adopts a more specific, nuanced performative 
model: that of affective labour - which is to say, immaterial labour that produces, as a good, the manipulation of affect; ease; wellbeing; satisfaction; passion; connectedness; and community. The emergence of affective labour as a dominant paradigm (at least in the developed West) has not only economical, but serious and tangible political consequences. According to Hardt, affective labour effectively shapes a new 'form of life': one in which labour produces 'collective subjectivities, socialities, and society itself' (Hardt, 1999, p. 90). In other words, immaterial labour, and its related affective labour have become, in the context of global capitalism, the typical modes of wealth and subjectivity production: it is through immaterial and affective labour that we generate ourselves as social and cultural subjects.

A consequence of the pervasiveness and identity-forming power of the immaterial forms of affective labour is their omnipresence in the life of the individual: it has become increasingly more difficult to make a distinction between work time and leisure time in at least two ways. First of all, the expansion of precarious work, self-employment and unpaid volunteering (upon which many sectors, including museums, rely for survival) has led to a diffuse state of permanently being on the job: 'life becomes inseparable from work' (Lazzarato, 1996, p. 137). Also, and more relevant to the ends of this essay, we witness an expansion of labour into domains and activities that have historically been defined as 'leisure': the 'temporality of life becomes governed by work' (Gill \& Pratt, 2008, p. 17) because virtually every non-work activity can ultimately be exploited as a source of immaterial goods, provided through regimens of affective labour. This is particularly true when we turn to the ever expanding realm of online, digital leisure: 'in the participation economy of Web 2.0 'free time' becomes 'free labour' as people produce and upload content for Facebook, Bebo and YouTube, modify games for giant multinational corporations and leave data trails that are 'informational goldmines' on Google and Safari, etc' (Gill \& Pratt, 2008, p. 17). Immaterial and affective labour in the digital realm is not limited to waged programmers or designers, as any and all members of the prosumer class ceaselessly produce immaterial goods through their performance of affects (Ritzer \& Jurgenson, 2010).

Autonomist researcher Tiziana Terranova discusses the tendency of immaterial labour to colonise the digital life of the subject, generating the 'informatised service worker', also termed by her the 'NetSlave' (2000, p. 36). Longer work hours, the blurring of the line between work and free time, the tendency for work and the workplace itself to become bathed in an affective light are all hallmarks of the immaterial service economy's desire to ascribe for the ends of capital the whole of the human being, well beyond prescribed work hours. In a nutshell, immaterial labour, being not merely (contractual) but also affective, tends to colonise the subject, with the consequences described by theorist Maurizio Lazzarato: 'difficult[y] of distinguishing leisure time from work time'; the worker as 'responsible for his or her own control and motivation'; that 'we should all become subjects' as 'one has to express oneself' (Lazzarato, 1996, p. 137).

Seeking productive expression, the digital immaterial labourer is exemplary of the immaterial economy at large, in her tireless and ceaseless production of information, networks and relationships between herself and other cultural and social agents. Terranova states that: 


\begin{abstract}
“...the NetSlaves are not working only because capital wants them to; they are acting out a desire for affective and cultural production that nonetheless real just because it is socially shaped... the moment where this knowledgeable consumption of culture is translated into productive activities that are pleasurably embraced and at the same time often shamelessly exploited" (Terranova, 2000, p. 36).
\end{abstract}

While Terranova's argument largely addresses waged digital workers, we should understand that the range of digital affective practises and pleasurable productive activities extends well beyond wagesanctioned production, into activities that few would recognise as work proper. This is particularly true in the context of Web 2.0, predicated as it is on activity and productivity as a hallmark of empowerment and self-affirmation: as, for example, Coté and Pybus' study of Myspace usage by teens shows, even a seemingly leisurely activity such as shaping up one's online social presence fits perfectly within the cogs of immaterial and affective labour: users 'expand their cultural and communicative capacities by constructing online subjectivities in an open-ended process of becoming' (Coté \& Pybus, 2007, p. 88), performing a labour that is both immaterial and markedly affective; the immaterial fruits of such activities can then be exploited by representatives of global capital in order to produce wealth in the form of new capitalist subjects, and exploitable user metadata.

\title{
'Playbour' and crowdsourcing as productive play
}

The insights of Italian Autonomists and critiques of free labour in the digital economy have seen application as tools for enquiry and challenge in the most varied aspects of digital and online production, to the point where the interconnectedness of all labour under capital's immaterial and affective flows of labour can potentially be utilised in order to build cross-sector critiques that find justification in the replicated qualities of the required labour. One case that should have great resonance to the museum field is the critique of labour in the context of games initiated by Julian Kücklich (2005), and then taken forward by game theorists such as lan Bogost (2011) and Mia Ridge (2011).

Kücklich detects, since the past decade, a novel tendency within games, ignited by the successful commercialisation of mods such as Counterstrike and, later on, Team Fortress: the progressive tendency toward a deeper interpenetration between in-house commercial products and non-commercial elements produced by consumers (2005). This interpenetration has tangible benefits for games developers: mods extend the shelf life of the product, introduce innovations that the company could not have thought of and, most important of all, mods increase customer loyalty by generating a community around a developer (Lipshin, 2011, p.4). Essentially, a chain of affects is generated by this new inclusion of the user within the production process: the modder has created and performed relationships through her free, unpaid labour that the game company can appropriate and deploy for material gain, but also enhanced public image, customer retention and what could be loosely defined as 'street cred'.

Modding as an exploitable activity might seem, at first, to have very little relationship with museum activities - or, more generally, with public engagement in the cultural, not-for-profit sector. We must keep 
in mind, however, the all-encompassing nature of immaterial and affective labour in our contemporaneity: while there might be no perfect coincidence between modding a first-person shooter, and tagging gallery artworks online (in fact there are, as we will see, key divergences with significant consequences), the two endeavours share the underlying the colonisation of traditionally not work-related times and tasks, which are co-opted for the generation of material and immaterial capital. The 'missing link', in my opinion, is a kind of game that, more closely than Kücklich's modding, resembles they type of public engagement traditionally sought by museums crowdsourcing: that is to say, casual gaming.

Jason Lipshin states that 'the broad transformation from Fordist to post-Fordist economies in late capitalist societies has transformed labour from an activity restricted to the enclosed space of the factory, to a multiplication of activities expanding into numerous spheres of ambient life - often under the auspice of play' (Lipshin, 2011, p.3). Therefore, not only the digital activity of gaming proper, but gaming as a paradigm of interaction, creation and consumption has been subsumed by capital in order to create new areas of agency and, occasionally, exploitation: 'it is by co-opting the smooth veneer and slippery signifiers of 'play' that contemporary labour can hide under playfulness, and play can become more laborious, allowing Julian Kücklich to coin the neologism "playbour"' (Lipshin, 2011, p.4).

The crux of the matter is that the ideology of gaming and leisure time as grounds for exploitation that Lipshin and the others articulate is ubiquitous throughout society's productive apparatus: it limits not itself to industry, but colonises culture, psychology and politics; sometimes it does not even require a proper game-like activity in order to be deployed. Lipshin's 'convergence of work and play' thrives on activities that possess selected traits of a game, even when not being games proper (Lipshin, 2011, p.3). This can go in both directions: an activity can present itself as a game, while actually being labour of some kind; and a traditionally non-game task can be made acceptable and engaging with the inclusion of game like traits (competitive ladders; rewards at fixed points reminiscent of 'levels'; encouragement toward friendly challenges; and so on).

As mentioned, the paramount example of a contemporary activity sitting between work and play - or, rather, constituting quasi-work disguised as play - is so called 'social gaming'. Lipshin follows his critique of the convergence of production, consumption and play by closely looking at one of the most popular online social games, the Facebook app Farmville (2011). Consisting both of an activity (the 'farming') and a resulting social display (showing your friends on Facebook the results of your gaming sessions), '[Farmville] is able to use rewards as a cheerful veneer to what is in fact an interface which inherently devalues the act of play into labour' (Lipshin, 2011, p.4). While the raising of cute, starry-eyed animals might seem galaxies away from the Fordist worker's endless pulling of a lever in a car factory, according to Lipshin the two activities have much in common: specifically, the mechanical and repetitive play-style that social games like Farmville promote, which reproduces the same action for the same, incremental but qualitatively constant outcome in exchange for 'a fantasy of individual empowerment' (Lipshin, 2011, p.9). Essentially, the repetitive, labour-like task that lies behind the game's rhetoric pays for time investment in subjectification and legitimisation of a personal, and digitally social nature; also, the rearrangement of in-game items in a compulsive, cumulative fashion 
suggests that part of the game's affect also relies on the elaboration of identity through - in this case, digital - the compulsive production of data and artefacts: 'players act as bricoleurs of their own identity, appropriating and recontextualising virtual consumer items as signifiers of their varied lifestyles and ideologies' (Willett, 2008, p.54).

The question is, then, does museum crowdsourcing display both the laborious traits, and the drive toward gamification that would make an immaterial and affective labour critique applicable? Observation of some celebrated crowdsourcing platforms, deployed by outstanding global institutions, would suggest a positive answer.

\section{Playful crowdsourcing in the digital museum}

Museum crowdsourcing is hardly under-researched, being a staple of global museum conferences, as well as a frequent topic of discussion in online fora and newsletters. Existing commentary on museum crowdsourcing, however, seems to be rather narrow in scope, concerning itself chiefly with the eminently practical matters of functionality, deployment and duplicability. Insufficient attention has been paid to the formal qualities of the online crowdsourcing interactive experience, and the interface affordances of museum crowdsourcing platforms are generally assessed only in force of how well they encourage or discourage the production of information and metadata.

There are, of course, exceptions. One trajectory, explored by commentators such as Mia Ridge (2011) and Jane McGonigal (2008), is the contextualisation of crowdsourcing and other assorted social online activities in relation to game and gaming: as we have seen in the previous section, under the rule of immaterial and affective labour there certainly exists a link between labour and play. We might, therefore, use discussions of museum crowdsourcing as gaming in order to also unveil museum crowdsourcing as labour, to suggest that the former dynamic is deployed in service of the latter.

Museums seem to have two main rationale for seeking to shape their crowdsourcing activities according to the dictates of what Deterding terms gamification, the 'use of game design elements in non-gaming contexts to improve user experience' (2011, p.1). On one hand, one can see the influence of constructivist learning and its attention toward the performative and cumulative aspect of information production (Hein, 2013; Hellin-Hobbs, 2010). Also, the museum has all to gain from embracing 'one of the most important materials of the future', given that games have the potential to '[make] ordinary people feel like superheroes', fighting the disorientation and disenfranchisement that sometimes accompanies the museum experience (McGonigal, 2008). The expansion of gaming as a pervasive social activity at all levels seems to run a path that is parallel to the museum's embracing of the visitor's agency and active involvement in knowledge co-creation as empowering and functional to the museum's own mandate.

There might be, however, one other implicit reason why gaming and gamification of crowdsourcing might be enticing to the museum: game-like activities seem an ideal avenue for museum to introduce the visitor into the museum's economy - which is to say, involve them in playful labour that generates affect and a sense of involvement in the visitor, as well as returning visits and web site accesses for the 
museum.

A striking feature of even the most quantitatively successful and professionally acclaimed museum crowdsourcing initiatives (although this could be generalised to crowdsourcing as an endeavour) is the laborious and repetitive nature of the underlying task the user is asked to perform. Specific deployments vary, and range from the V\&A Beta Crowdsourcing, where users are asked to perform serially the very uncreative activity to select a certain image cropping, generating virtually no content ("V\&A Beta Crowdsourcing", n.d.); to the other extreme, such as the Brooklyn Museum's Freeze!Tag minigame, where users are asked to confirm or veto on metadata produced by other users, therefore needing to think contextually and creatively. In between lays a galaxy of initiative which requires the user to produce large quantities of data, usually as a reaction to an object's formal qualities rather than its history or context, which are then incorporated as collection metadata by museums. As I will discuss later, this is not the exclusive, or the most creative use of crowdsourcing that museums have done; nonetheless, the serial production of metadata by users remains one of the big institutional attractors toward crowdsourcing. What should worry us is the realisation that, stripped of the gamification veneer that most of these crowdsourcing initiatives deploy, the underlying activity worryingly resembles the mechanical, serial, repetitive labour of Fordist factories once; FarmVille and other social games nowadays.

What are the actual gamification strategies that some museum crowdsourcing initiatives have adopted, in order to foster affect and, therefore, encourage immaterial and affective toiling? Gamification is usually featured at the level of the crowdsourcing tool's interface, and most times also at the level of the meta-context in which the actual crowdsourcing activity is located. The amount of gamification will, of course, vary based on the tool; and this, in turn, will have an impact on the level of affect, investment, and user retention generated.

\section{Steve Tagger}

One of the paradigmatic prototypes of museum crowdsourcing tools is Steve Tagger, a prototype platform developed by the steve.museum initiative and available at http://tagger.steve.museum/. The splash page features a short blurb about the aims and outcomes of the tagging tool; a bar with a few statistics on the project, including the total amount of images; the total amount of terms generated; the number of registered users; and a list of the seventeen institutions that have provided images of artworks. Through four tabs and a search bar, the images are searchable by browsing them; by selecting a previously assigned term (including some from a 'top 100' and a 'top 1000' list); by museum of origin. Once an artwork is selected, we are taken to that artwork's specific page. Here, basic archival records are provided (title, origin, period, institution) along with a zoomable image. Above those, one can find a field in which to enter a tag. The full list of tags for the item up to that moment can be found in a tab under the main field, along with more specific metadata, a link to the grouping (collection) the item is part of, and links to similar items. On the side, one can add the image to a set, link it on Facebook or Twitter, or email the Steve Tagger staff. Added tags appear immediately in the appropriate tab under the image. Finally, one can click on an appropriate thumbnail in order to move to the next image. 
At first, the activity proposed might seem to have little to do with serious games, or with play in general. Upon repeated use, one of the emerging characteristics of the type of labour Steve Tagger requires is its repetitiveness: we are asked to tag images appearing in random order, through the course of an uniformly mechanical activity that resembles labour far more than play. Yet, while the activity can hardly be classified as a 'game' proper, there is more than one element that points at gamification as the key reward mechanism for what would seem, upon first experience, hardly an inherently rewarding activity for non museum-inclined people. The choice to display top 1000 and top 100 terms, with the user's own terms standing out in colour, could be construed as an instance of 'gamification'- the appearance of the user's own picked terms on the front page of the project affectively rewards the participant, as it bridges the 'distance' that exists between the individual and the institution, legitimising the former's choice of descriptive terms and allowing a metaphorical 'embracing' of the user by the latter; it also implicitly connects the single user to a larger network of participants with whom, albeit anonymously, she can potentially enter in competition, in an instance of 'networked playfulness' that heavily echoes the individual activity/collaborative framework typical of much casual social gaming, and social media platforms in general; finally, it provides a reward and a means to quantify one's participation and progression within the structured activity of Steve Tagger, therefore generating a game-like goal to the otherwise droll activity of churning out terms, one picture after another (Lipshin, 2011; Coté and Pybus, 2007). Finally, the possibility to create sets of items, and then save them for future reference, doubles as an information gathering tool for the software, as well as a way for the user to increase accomplishment by generating a kind of 'trophy gallery', which acts also as an incentive to return for further tagging.

Aligned with the steve.museum project's explicit aims of improving collections access, searchability, and fostering interest in museum collections, the Steve Tagger application can be read in the context of digital labour practises, affective labour, and 'gamification' of quasilabour activities. The quick, repetitive task that Steve Tagger's 'nofrills' interface encourages deploys the user-as-digital-labourer effectively, maximising the production of terms per amount of time spent. The activity's potential for alienation (through obvious free labour exploitation) is however mitigated on various levels, by game - like elements. The labour relationship is, to a certain level, mutually beneficial: an hypothetical museum team adopting Steve Tagger can generate, with little expenditure and within a reasonably short amount of time, a wealth of metadata which will not only corroborate existing museum expertise, but also will increase visitor access, return rates and revenues by bridging the 'semantic gap' and, more generally, humanising the museum. At the same time the user, through the engagement of games, gets a sense of accomplishment and belonging to the socially acceptable intellectual paradigm that the museum, art and culture are part of - which is to say, the user gets building blocks for social, cultural and political subjectification.

\section{V\&A Beta Crowdsourcing}

There are other crowdsourcing platforms that take a more marked stance toward laborious activity and gamification - in either direction. The V\&A Beta Crowdsourcing does away with most if not all 
gamification elements, putting the accent (perhaps inadvertently) on the laborious aspect of the required crowdsourcing activity. The user is presented with a selection of two or more digital reproductions of an artwork, of typically wildly varying quality. Since the picture frame on an object's official records page has to feature only the best quality images, the crowdsourcing element consists of performing the relatively simple task of picking the 'best' image to be featured on the object's record page. While the meaning of what 'best' might mean is left somewhat to the user's speculation, this still wouldn't prove to be a significant difficulty, as usually we're not shown more than three images per object, and at least one will be of such evidently poor visual quality that it will be ruled out almost instantly.

The V\&A Beta Crowdsourcing is probably as close a crowdsourcing activity can get to labour proper. While the image selection screen provides basic archival information, this data is largely irrelevant to the task the user is asked to perform: that a marble be a Greek antique or a Roman copy has no bearing on the simple task of selecting the image in which the sculpture is not underexposed and, even if it was, the interface makes no effort to suggest so. What the object actually is, what it represents, and its history and politics are mostly irrelevant in the context of the demanded task: all the user is expected to do is choose the most visually compelling crop, one object after another, moving on to another and completely unrelated object once a micro-task is done. Overall, the activity bears a striking resemblance, in more than one extent, to the simple tasks required from the worker of an hypothetical assembly line: performing an extremely simple job, one instance after the other, with no apparent diversion from a perpetually undifferentiated, static stream of labour devoid of creative engagement.

The crowdsourcing activity the $V \& A$ requires lays bare the fundamentally laborious nature of digital crowdsourcing activities, their belonging to the sphere of 'immaterial labour'. Is it possible for a crowdsourcing activity of this variety to foster affect, a sense of cultural and social belonging, relationships and subjectivity? This would seem to be hardly the case. One obstacle is the depersonalisation and decontextualisation of the task that is required, and the distancing effect from the museum as 'affect machine' that it has on the user. A key dynamic that encourages involvement in museum crowdsourcing is the possibility for subjectification and cultural legitimation that it offers, progressively constructed through labour that has a tangible impact on the museum and its cultural economy. In other words, commitment is built by 'incorporation' of the user within the museum's inner workings through useful tasks.

Yet, an useful activity in and for itself is not enough. As a crowdsourcing task, language tags generation offers a motivational element that the V\&A's image selection task cannot replicate: content generation. One of the features that make verbal tag generation relatively more demanding for the user - and, therefore, more precious for the museum - is the level of difficulty and choice that they require. Unlike mere selection of a better looking picture among a group, an exercise in which many are likely to be already apt based on daily personal experience with digital media, assigning tags to a foreign object requires a degree of independent thinking, balanced by a necessity to have the tag make sense in the context of the object, and other tags assigned. Essentially, when the crowdsourcee is asked to assign verbal tags, she is asked to generate semiindependent content (Ridge, 2011). Such a task requires 
concentration, awareness and knowledge: it is, in many ways, prototypical of a game-like activity even when a formal game structure is not in place - and, as the previously constructed discourse on the affective nature of game-like activities and 'feel good' tasks in general suggests, this sense of a tangible contribution, that benefits the museum but also provides encouragement and subjectifies the user, is likely to result in greater returns and more loyalty to the task (Simon, 2008).

\section{Tag! You're It! and Freeze Tag!}

Other crowdsourcing projects rely heavily on gamification in order to encourage flow, engagement and affect toward laborious tasks. The Brooklyn Museum has adopted this strategy and capitalised on it through two interesting crowdsourcing platforms, Tag!You're It and Freeze!Tag, and the ingenious social invention that ties the two together, the Posse. Rather than being anonymous, the Brooklyn Museum's newly registered user becomes a member of the museum's crowdsourcing Posse, a formally recognised group of volunteers that interact through their own social micro-platform and engages in crowdsourcing activities. The registered member's identity within the Posse also functions as a game avatar of sorts members of the Posse are pitted against each other in a collectionencompassing crowdsourcing game, in which they vie for first place in a friendly competition, reminiscent of competitions between teams in the various '@home' distributed computing initiatives. Once registered with the Posse, the user has the option to switch between two different and independent crowdsourcing games: Tag! You're It! centres around assigning tags to objects (“Tag! You're It!", n.d.); while Freeze Tag! requires the user to approve or veto challenged tags (“Freeze Tag!", n.d.).

The layout for Tag! You're It is relatively simple. On the left of the screen, an artwork image and basic archival records are provided. A middle column provides formatting guidelines for entering tags (they can be separated by spaces, or strung together by double quotes) as well as an option to skip the current artwork. On the right side of the screen, the tagging statistics of the user appear: number of total tags, and number of objects tagged; a 'Tag-o-meter' that displays how many tags you need to overcome the closest ranking Posse member, and the current total of the highest scoring Posse member; and an option to conclude the current session, which will also display terms matching with other members.

Freeze Tag! follows similar coordinates as Tag! You're It!, yet is altogether a slightly different type of activity. The crowdsourcing task consists not of assigning tags, but rather of confirming or refuting the validity of tags assigned by other Posse members. In Freeze!Tag, along with images, the Posse member is provided with more information about the artwork, as well as multiple pictures: this seems to be necessary, as challenging a tag might require additional, in-depth information about an artefact. For each object, a series of challenged tags is given, with three options for each: a red button to reject the tag, a green one to keep it, and a yellow one in case of indecision. A column shows the total tags that the current Posse user has judged, tallied as a score: the user gets additional points if her decision agrees with other Posse members. Once a set amount of points has been accrued, the user is 'rewarded' with a humorous artrelated video (for example, after twenty points one might be 
rewarded with a ten minute snippet from a Salvador Dalì interview). The process of tag approval comes to resemble, therefore, a consensus-driven application of the 'collective intelligence' O'Reilly spoke about (2005).

In a blog post from August 2008, right when the project was unveiled for public participation, Brooklyn Museum's Chief of Technology Shelley Bernstein gives a description of the impetus that led to the development of Tag! You're It (Bernstein, 2008). Citing now defunct Google's Image Labeler as a precedent, she highlights the mutual advantage in having the public perform tagging upon the online collection: in a phrase, 'a simple and fun activity for the Posse which, in turn, establishes better relevance for the visitor trying to search our collection. Sweet!' (Bernstein, 2008). Therefore, at least in intention, the Brooklyn Museum's crowdsourcing activity does not seem to differ much from the precedent established by Steve Tagger: mutual gain for the museum and the public, as the former can transfer a hefty workload (classifying, archiving, updating of metadata) on the latter, who in turn is rewarded by better museum information, as well as a healthy does of 'fun'. Where Tag! You're It goes beyond Steve Tagger's, and certainly V\&A Beta Crowdsourcing's approach, is in the deployment of the most engaging aspects of the 'serious game' format in order to justify and naturalise the free labour that it requires from its public. Also, more than both previous illustrative cases, the Brooklyn Museum's project relies on subjectification and affectivity in order to foster loyalty to crowdsourcing's laborious task.

A distinctive trait not only of Bernstein's blog post, but also of the application itself is the highly informal language it employs. The abundant use of exclamation marks, all the way into the applications' own names, generates impact but also implies a rhetoric of friendliness and inclusion, the enthusiasm one would use with a friend - or a Posse member - sharing a passion. In the Tag! You're It! application, the user does not click on 'skip to next image', but rather clicks on 'Nah, skip this one'; ending the section requires to select the statement 'That's it, I'm done for this session. Now let me see matches and standings!', as if one was to directly address the application as a peer, or a buddy. The rhetoric is one of impact, immediacy, friendliness and engagement on a first-name basis: coupled with the names of the two crowdsourcing activities themselves, the language the project deploys is that of playfulness and lively interaction that is typical of games.

The crowdsourcing platforms' structure only serves to reinforce this perception, and make the connection between the required activity and play even stronger. After every session, a tally point is given, and compared to other players', in a quest to become a 'super-tagger' of sorts; also, the highest scoring taggers are prominently displayed on the front page of the Posse's sub-site. This short-session format, after which a tally is given in order to beat a score (be it your own or somebody else's) is heavily reminiscent of the flow one would associate with an arcade game like Super Mario: relatively short 'levels', along with a count-up that gives the user a clear sense of her relative standing - feeding further the drive to achieve, and at the same time providing tangible proof of impact. Session after session, the heavily 'gamified' and playful nature under which the repetitive task is disguised effectively makes this 'grindy' immaterial labour also an affective labour, which possibly generates a degree of engagement, flow, identification with the Posse by way of rivalry and challenge. It comes as no surprise, therefore, that Posse members in 
total provided over 58,000 terms, with some members providing as many as 8,323 , and that the quality of the terms was deemed by the museum to be quite high (Bernstein, 2009). Such a mass of high quality work would have been difficult to achieve without an activity and context that encouraged engagement, entertainment and affect.

\section{Museum crowdsourcing and alternatives to exploitation}

Once I have suggested, and provided rationale, for the thesis that museum use 'gamified' crowdsourcing platforms in order to encourage and upkeep a flux of immaterial labour of the affective kind, the big question then becomes: does this kind of activity either possess, or potentially entail the risk of exploitation? The userfriendly, empowering veneer of crowdsourcing rhetoric should not trick us into thinking such a question as unnecessary or hindering: outside the museum, crowdsourcing's 'Wild West days of exploitation' are waning (Hodson, 2013, p.22), and calls for scrutiny of its ethical dimension grow louder (Deng \& Joshi, 2013). 'Volunteering [having] a long and consolidated tradition, and unpaid work [being] done for a common good' (Carletti et al., 2013, p. 225) in the museum does not automatically dispense museums from examining the ethics even of voluntary user engagement - considering, additionally, that the museum sector's heavy reliance on unpaid work has been heavily critiqued by the same Autonomists that put under critique immaterial and effective labour (Muehlebach, 2011).

My perception is that museum crowdsourcing as a typology displays peculiarities that not only keep at bay the risk of exploitation of immaterial and affective labour; but, additionally, could exist as an example of ethically responsible crowdsourcing in general. In first instance we have already seen that, at their best, museum crowdsourcing platforms encourage the production of immaterial goods through the deployment of a labour that is not only affective, but also subject-enhancing and in which the playful elements mitigate, rather than merely disguise, the laborious process. One example is the Brooklyn Museum's Posse: the crowdsourcing activity's gamified nature, in this case, generates a community that, at least potentially, transcends the activity proper, given that participants have their own searchable user page, avatar and profile with contact information. The generated community serves well the affective labour needs of the museum, fostering engagement and intra-group competitiveness; yet, it also possesses functional aspects that are not directly related to the crowdsourcing activity, and therefore potentially escape its most labour-driven and exploitative logic.

In second instance, the museum context also presents many examples of 'gamified crowdsourcing' serving tasks that, while formally still labour, stray from the repetitive alienation of seriality. Usually, these more complex and involved kinds of crowdsourcing, much like Brooklyn Museum's Freeze!Tag, ask the user to make complex and context-laden decisions that lead to the creation of substantial and layered original content. Some examples are the Royal Pavilion \& Museum's Map the Museum, where users were asked to produce original content by putting in relationship places and collection objects ("Map the Museum", n.d.); the Brooklyn Museum's Click! A crowd-curated exhibition (2008), where the crowd was asked to evaluate submissions for a photography exhibition; and the Smithsonian's AR game Ghost of a Chance (2008-2010), where 
users were asked to create and submit artworks as part of their involvement.

In final instance, however, what poses museum crowdsourcing as a potentially empowering example of ethical crowdsourcing is the very life-cycle of the immaterial good that is produced. A basic tenet of exploitation from a Marxist point of view, to which Autonomism largely subscribes, is the systematic expropriation of the surplus value generated by labour: that is to say, owners of the means become also owners of the surplus value generated by the labourers (Marx, 2004). If we take for true that, under crowdsourcing's regimen of immaterial and affective labour, the crowdsourcee is 'paid' in enjoyment, self-affirmation and community, then it would be the information, tags and metadata that are theoretically expropriated by the museum. This is, however, clearly not true in the case of museum crowdsourcing: while perhaps not immediately, the immaterial goods produced by the user's affective labour are returned, eventually, in the guise of better tailored, detailed and relevant information, which becomes publicly accessible. Furthermore, it could be stated that the user receives this surplus return in an augmented form: according to constructivist learning, the user's involvement in the co-creation of information fosters better learning and retention; so that, in theory, the surplus return will be all the more significant and understandable to the crowdsourcee, as she had a hand in its very production (Hein, 2013).

The problem becomes, then, one of process and means: how can museum develop crowdsourcing platforms that, while serving ultimately the visitor's end, do not pose repetitive and, in the long run, alienating and laborious activities as the inherent logic of the crowdsourcing activity? Gamification can play an important part in 'humanising' the crowdsourcing process, but only if done right. The dangerous possibility of play as a thin disguise for labour should be avoided, in favour of a gamification that plays on games' inherent user-serving strengths: variety, unpredictability and productive creativity as an inherent value.

\section{References}

Bernstein, S. (2008, August 1). Tag! You're it! [Blog post]. Retrieved from https://www.brooklynmuseum.org/community/blogosphere/2008/08/ 01/tag-youre-it/

Bernstein, S. (2009, May 21). Crowdsourcing the Clean-Up with Freeze Tag! [Blog post]. Retrieved from http://www.brooklynmuseum. org/community/blogosphere /2009/05/21/crowdsourcing-the-cleanup-with-freeze-tag/

Bogost, I. (2011, May 3), Persuasive games: exploitationware. [Blog post]. Gamasutra: The art \& business of making games. Retrieved from http://www.gamasutra.com /view/feature/134735/persuasive_games_exploitationware.php

Carletti, L., Gabriella G., \& McAuley, D. (2013). Digital humanities and crowdsourcing: An exploration. Selected papers from Museum and the Web, 13, 223-236.

Click! A crowd-curated exhibition. (27 June - 10 August, 2008). Brooklyn Museum. Retrieved from http://www.brooklynmuseum.org/ exhibitions /click/

Coté, M., \& Pybus, J. (2007). Learning to immaterial labour 2.0: MySpace and social networks, Ephemera: Theory and politics in organization. 7(1), 88-106.

Deng, X. N., \& Joshi, K. (2013). Is Crowdsourcing a Source of Worker Empowerment or Exploitation? Understanding Crowd Workers' 
Perceptions of Crowdsourcing Career, CHI Session, Paris.

Deterding, S., Sicart, M., Nacke, L., O'Hara, K., \& Dixon, D. (2011). Gamification. using game-design elements in non-gaming contexts. Proceedings of the 2011 annual conference. Extended abstracts on Human factors in Computing Systems, Part 2, pp. 2425-2428.

Duncan, C. (1995). Civilizing Rituals: Inside the Public Art Museum, UK: Routledge.

Freeze Tag! (n.d.). Brooklyn Museum. Retrieved from http://www.brooklynmuseum.org /opencollection/freeze_tag/start.php *

Ghost of a Chance. (2008-2010). Smithsonian Institution. Retrieved from http://www.ghostsofachance.com

Gill, R., \& Pratt, A. (2008). In the social factory? Immaterial labour, precariousness and cultural work. Theory, Culture \& Society, 25(78), 1-30.

Hardt, M. (1999). Affective labor. Boundary 2, 26(2), 89-100.

Hein, G. E. (2013). Learning in the Museum, UK: Routledge.

Hellin-Hobbs, Y. (2010). The constructivist museum and the web. Proceedings of the 2010 international conference on Electronic Visualisation and the Arts, pp. 72-78.

Hodson, H. (2013). Crowdsourcing grows up as workers unite. New Scientist, 217(2903), 22-23.

Kücklich, J. (2005). Precarious playbour: Modders and the digital games industry, Fibreculture 5.

Lazzarato, M. (1996). Immaterial Labour. In M. Hardt \& P. Virno (Eds.), Radical thought in Italy: $A$ potential politics (pp. 133-147). Minneapolis: University of Minnesota Press.

Lipshin, J. (2011). Casual Labor: How Farmville (2009) Converges: Production, Consumption, and Play (B.A. Candidate, Cinematic Arts Critical Studies, University of Southern California). Retrieved from http://storm.usc.edu / lipshin/CV_PDF/UWC_2011_Submission_Final.pdf

Map the Museum (n.d.). Royal Pavilion \& Museums, Brighton \& Hove. Retrieved from http://mapthemuseum.org.uk/\#14.00/50.8300/0.1400

Marx, K. (2004). Capital: A critique of political economy. Boston, MA: Digireads. com Publishing. (Original work published 1867)

McGonigal, J. (2008). Gaming the Future of Museums [PowerPoint slides]. Retrieved from http://www.slideshare.net/avantgame/gaming-thefuture-of-museums-a-lecture-by-jane-mcgonigal-presentation

Muehlebach, A. (2011). On affective labor in post-Fordist Italy, Cultural Anthropology. 26(1), 59-82.

O'Reilly, T. (2005, September 30). What is web 2.0. [Blog post]. Retrieved from http://www.oreilly.com/pub/a/web2/archive/what-is-web-20.html

Ridge, M. (2011). Museum Games and UGC: Improving Collections Through Play [Blog post]. Retrieved from http://www.miaridge.com/museumgames-and-ugc-improving-collections-through-play/

Ritzer, G., \& Jurgenson, N. (2010). Production, Consumption, Prosumption The nature of capitalism in the age of the digital 'prosumer', Journal of Consumer Culture 10(1), 13-36.

Romeo, F., \& Blaser, L. (2011). Bringing citizen scientists and historians together. In J. Trant \& D. Bearman (Eds). Museums and the Web 2011: Proceedings. Toronto: Archives \& Museum Informatics. Retrieved from http://www.museumsandtheweb.com/mw2011/papers/bringing_citiz en_scientists_and_historians_tog

Simon, N. (2008, November 6). Two Tagging Projects that Make Sense [Blog post]. Retrieved from http://museumtwo.blogspot.it/2008/11/twotagging-projects-that-make-sense.html

Tag! You're It! (n.d.). Brooklyn Museum. Retrieved from http://www.brooklynmuseum.org/opencollection/tag_game/start.php*

Terranova, T. (2000). Free labor: Producing culture for the digital economy, Social text 18(2), 33-58.

Terras, M., \& Causer, T. (2014). Crowdsourcing Bentham: beyond the traditional boundaries of academic history. International Journal of Humanities and Arts Computing, 8(1), 46-64.

V\&A Beta Crowdsourcing (n.d.). V\&A Search the Collections. Retrieved from 
http://collections.vam.ac.uk/crowdsourcing/

Willett, R. (2008). Consumer citizens online: Structure, agency, and gender in online participation, Youth, identity, and digital media, 49-69.

*Editor's note: The above-mentioned Brooklyn Museum tagging games "Tag! You're It!" and "Freeze Tag!" were retired by the museum after the article was submitted for publication

\section{Abstract}

Through the lenses of Autonomism and playbour theory, the essay re-reads the museum's investment in crowdsourcing as one expression of current, culture-wide trends toward the expansion and naturalisation of immaterial and affective labour: the user's work is harnessed through activities that sit between work and leisure, and the museum gains in capital and legitimisation, while the user is paid in subjectification, affirmation and intellectual currency. While crowdsourcing - in current museum literature - is usually assumed a priori to be advantageous and ethically empowering for museums and audiences, an interpretation of this instrument as a radical expression of labour cautions us against the ever-present danger of exploitation, less visible but nonetheless tangible.

Key words: playbour, gamification, Web, Autonomism, crowdsourcing

\section{Resumen}

\section{Crowdsourcing en el museo como entretenimiento productivo}

A través de la óptica del autonomismo y de la teoría del playbour, este ensayo reinterpreta la inversión que el museo realiza en crowdsourcing, como una expresión de las tendencias actuales hacia la expansión y naturalización del trabajo inmaterial y afectivo: el trabajo del voluntario es aprovechado a través de actividades que se sitúan entre el trabajo y el ocio productivo. El museo gana en capital y legitimación y el voluntario es retribuido en subjetivación, afirmación personal y crecimiento intelectual. Mientras que el crowdsourcing es considerado usualmente y a priori - en la literatura sobre museos vigente - como ventajoso y como un medio de empoderar éticamente a las audiencias del museo, una interpretación de esta herramienta como una forma de trabajo no remunerado nos advierte contra el peligro siempre presente de explotación laboral, menos visible pero no por eso menos tangible.

Palabras clave: playbour, gamificación, Red, autonomismo, crowdsourcing 